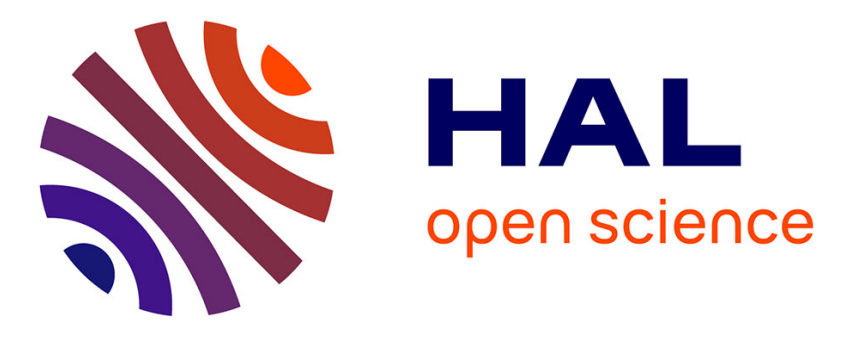

\title{
Quantification of the available acid sites in the hydrocracking of nitrogen-containing feedstocks over USY shaped NiMo-catalysts
}

Pedro S.F. Mendes, João Silva, M. Filipa Ribeiro, Christophe Bouchy, Antoine Daudin

\section{To cite this version:}

Pedro S.F. Mendes, João Silva, M. Filipa Ribeiro, Christophe Bouchy, Antoine Daudin. Quantification of the available acid sites in the hydrocracking of nitrogen-containing feedstocks over USY shaped NiMo-catalysts. Journal of Industrial and Engineering Chemistry, 2019, 71, pp.167-176. 10.1016/j.jiec.2018.11.019 . hal-02409000

\section{HAL Id: hal-02409000 \\ https://hal-ifp.archives-ouvertes.fr/hal-02409000}

Submitted on 4 Jan 2021

HAL is a multi-disciplinary open access archive for the deposit and dissemination of scientific research documents, whether they are published or not. The documents may come from teaching and research institutions in France or abroad, or from public or private research centers.
L'archive ouverte pluridisciplinaire HAL, est destinée au dépôt et à la diffusion de documents scientifiques de niveau recherche, publiés ou non, émanant des établissements d'enseignement et de recherche français ou étrangers, des laboratoires publics ou privés. 


\section{Quantification of the available acid sites in the hydrocracking of nitrogen-containing feedstocks over USY shaped NiMo- catalysts}

Pedro S. F. Mendes ${ }^{a, b, 1 *}$, João M. Silva ${ }^{a, c}$, M. Filipa Ribeiro ${ }^{a}$, Christophe Bouchy ${ }^{b}$, Antoine Daudin ${ }^{\text {** }}$

${ }^{a}$ Centro de Química Estrutural, Instituto Superior Técnico, Universidade de Lisboa, Av. Rovisco Pais, 1049-001 Lisboa, Portugal

${ }^{b}$ IFP Energies nouvelles, Rond-point de l'échangeur de Solaize, BP 3, 69360 Solaize, France

'ADEQ-ISEL, Instituto Superior de Engenharia de Lisboa, Instituto Politécnico de Lisboa, $R$. Cons. Emídio Navarro, 1959-007 Lisboa, Portugal

*pedro.f.mendes@tecnico.ulisboa.pt; antoine.daudin@ifpen.fr ; +33 (0)4 37702989

This is the peer reviewed version of the following article: P. S. F. Mendes, J. M. Silva, M. F. Ribeiro, C. Bouchy, A. Daudin, J. Ind. Eng. Chem. 71 (2019) 167-176, which has been published in final form at https://doi.org/10.1016/i.jiec.2018.11.019.

\footnotetext{
1 Present address: Laboratory for Chemical Technology, Ghent University, Technologiepark 914, B-
} 9052 Ghent, Belgium. 


\section{Abstract}

The inhibition of Brønsted acid sites by nitrogen-containing molecules was quantified under industrially relevant hydrocracking conditions. This was achieved by testing bifunctional catalysts based on HUSY zeolite in cyclohexane hydroconversion. For ammonia partial pressures within $0.2-2.8 \mathrm{kPa}$, the percentage of inhibited Brønsted sites was superior to $98 \%$ at $623 \mathrm{~K}$. Significant reduction in the ammonia content caused rather moderate variations on the number of available sites. Conversely, a temperature raise from 600 to $640 \mathrm{~K}$ triplicated the vacant Brønsted sites due to the significant endothermicity of ammonia desorption. The inhibiting effect of ammonia can be therefore easily modulated by temperature.

Keywords: hydrocracking; HUSY zeolite; catalyst deactivation; ammonia; operando Brønsted acidity; bifunctional catalyst 


\section{Introduction}

The use of liquid fuels accounts for more than $30 \%$ of the whole energy consumption in the world. A particular suitable process to produce middle distillates (i.e. jet fuel and diesel) from heavy oil cuts is hydrocracking [1-4]. The typical feedstock is distillation vacuum gas oil (VGO) that may be mixed with heavy gas oils produced by other conversion units in the refinery [1]. VGO is mostly composed by aromatic and paraffinic compounds featuring a wide assortment of molecular weights (distillation range from $650 \mathrm{~K}$ to $820 \mathrm{~K}$ ). Other elements besides carbon and hydrogen can also be found on VGO. Particularly, sulphur and nitrogen are commonly present in polyaromatic molecules [1].

The hydrocracking of VGO involves a bifunctional heterogeneous catalyst comprising a hydrogenation/dehydrogenation $(\mathrm{HDH})$ and an acid function of Brønsted type. The HDH function is frequently granted by transition metal sulphide promoted with other metals (typically, Mo or $\mathrm{W}$ promoted with $\mathrm{Ni}$ or $\mathrm{Co}$ ). The Brønsted acid function is most commonly provided by a zeolite (usually shaped with alumina [5]). For a given zeolite and operating conditions, the behaviour of the bifunctional catalyst chiefly depend on the number of metal to the number of Brønsted acid sites ratio [5-10]. For relatively high ratios (i.e. HDH function is sufficiently active comparing to Brønsted acid function), the turnover frequency per Brønsted acid site and selectivity towards isomerization are maximal. Further increase of the number of metal to the number of Brønsted acid sites ratio will have a marginal impact on the catalyst performances $[5,7]$. In such case, the catalytic behaviour is governed by the properties of the zeolite, specifically the pore architecture and the characteristics of the Brønsted acid sites [2,11-20].

The behaviour of a bifunctional catalyst depends not only on its formulation but also on the operating conditions. For instance, when the feedstock is fed to the reactor, the properties of the catalytic functions can be greatly modified by the presence of inhibitors or poisons affecting, thus, the performance of the catalyst [21]. In the case of hydrocracking, nitrogen-containing molecules, are commonly at the origin of catalyst deactivation [1,21-29]. Typically, the organic bases present in the feed are firstly converted to ammonia, which is less basic, by a hydrotreating catalyst. For single-stage processes, in which no separation exists between the hydrotreating and hydrocracking stage, considerable amounts of ammonia are then fed to the hydrocracking catalyst reducing its activity [1].

Reports in literature have indeed confirmed a substantial reduction of zeolite-based catalyst activity in presence of $\mathrm{NH}_{3}[23,25,27-29]$, justified by the neutralisation of the Brønsted acid sites of the zeolite. This is due to the stronger adsorption of the nitrogen-containing molecules onto the Brønsted sites as compared to that of hydrocarbons. In industry, the reactor temperature is raised throughout the catalyst operation cycle to compensate the loss of activity caused by deactivation via, among others, coke deposition and ammonia adsorption [1]. Concerning selectivity, some studies have also pointed to an increase in the yield of either 
middle distillates (for VGO feedstocks) $[1,29]$ or feed isomers (for pure $n$-paraffins feedstocks) $[24,25,27,28]$ upon inhibition by nitrogen-containing molecules. Wisely controlling the inhibition of acid sites in industrial zeolite catalysts is, hence, of prime importance to achieve an optimal balance between the loss of activity and the enhanced selectivity.

Conversely, the amount of Brønsted sites available to catalyse hydrocracking reactions under industrially-relevant conditions have been scarcely, if at all, studied in literature. On the one hand, as the impact of the operating conditions on the amount of inhibited acid sites remains unknown, the operating conditions can only be optimized by trial and error. On the other hand, rational design of a catalyst is not feasible without precise information on the active sites available under reaction conditions. Only through quantification of the operando active sites it will be possible to establish reliable structure-activity relationship on which one can draw to design optimal heterogeneous catalysts.

Even though the detrimental role of ammonia on hydrocracking activity is well-known, the quantification of this inhibition effect under typical industrial reaction conditions is lacking in open literature. In this work, we aim at taking a step forward and quantify the amount of Brønsted acid sites effectively available under industrially-relevant hydrocracking conditions. In order to assess the amount of acid active sites available in reaction conditions, the NiMo zeolite-based catalysts were evaluated through a carefully selected model reaction. More specifically, it features a well-established kinetics which holds over broad ranges of conversion and operating conditions $[8,9]$. Different partial pressures of $\mathrm{NH}_{3}$ and reaction temperatures were employed enabling the quantification of the operando acid sites as well as the impact of the operating conditions on such amount. This study sheds, thus, light on the acid sites actually working in a hydrocracking reaction providing concomitantly a simple methodology to carry out such evaluation under industrially-relevant conditions.

\section{Materials and Methods}

\subsection{Catalyst preparation}

Zeolite HUSY (CBV720) was supplied by Zeolyst. The shaped support was prepared by mixingextrusion with boehmite employing a procedure published elsewhere [5]. The metals were introduced in the calcined support by incipient wetness impregnation with an aqueous solution of $\mathrm{H}_{3} \mathrm{PO}_{4}, \mathrm{Ni}(\mathrm{OH})_{2}$ and $\mathrm{MoO}_{3}$. The precursor solution was obtained after reflux at $363 \mathrm{~K}$ over 12 h. In solution, the $\mathrm{Ni} / \mathrm{Mo}$ atomic ratio was 0.40 and the $\mathrm{P} / \mathrm{Mo}$ atomic ratio was 0.48 . The impregnated solid was maturated during $12 \mathrm{~h}$. The material was then dried overnight at $493 \mathrm{~K}$ and calcined in an air flow of $1.5 \mathrm{NL} \mathrm{h}^{-1} \mathrm{~g}^{-1}$ at $723 \mathrm{~K}_{\text {over }} 2 \mathrm{~h}$ (heating rate of $5 \mathrm{~K} \mathrm{~min}^{-1}$ ). Ex-situ sulphidation was carried out over a part of the samples in order to characterize the NiMoS phase. The sulphidation took place at $623 \mathrm{~K}$ over $2 \mathrm{~h}$ using a heating rate of $5 \mathrm{~K} \mathrm{~min}^{-1}$, under a 
$\mathrm{H}_{2} / \mathrm{H}_{2} \mathrm{~S}$ flow (15 vol.\%) of $1.5 \mathrm{NL} \mathrm{h}^{-1} \mathrm{~g}^{-1}$ and the samples were sealed under a $\mathrm{N}_{2}$ atmosphere. Throughout this article, calcined samples will be denoted NiMo and sulphided samples will be denoted NiMoS.

\subsection{Catalyst characterization}

Quantitative elemental analysis was performed by $\mathrm{x}$-Ray Fluorescence. Samples were grinded and sieved into a granulometry under $200 \mu \mathrm{m}$. Measurements were carried out directly over powder samples in a Thermofischer Scientific Advant-X instrument.

Nitrogen adsorption-desorption measurements were carried out at $77 \mathrm{~K}$ on a Micrometrics ASAP 2010 apparatus. Before adsorption, zeolite samples were degassed under vacuum at $363 \mathrm{~K}$ for $1 \mathrm{~h}$ and then at $623 \mathrm{~K}$ for $4 \mathrm{~h}$. The total pore volume was calculated from the adsorbed volume of nitrogen at a relative pressure $\mathrm{P} / \mathrm{P}_{0}$ of 0.97 . The microporous volume was determined employing the $t$-plot method [30]. The mesoporous volume was obtained by the difference between the total pore and the microporous volumes.

The electron probe micro analysis was carried out in a JEOL 8100 equipment. The extrudates were embedded in an Specifix-40 epoxy resin (Struers, Ballerup, Denmark) that was prepolymerized to prevent carbon contamination [32] and polished to obtain a flat section. A thin conductive carbon layer was deposited to prevent surface charging effects. Samples were analysed using a $20 \mathrm{keV}$ and $100 \mathrm{nA}$ electron beam. For each sample, five profiles were measured on five different catalyst grains along the diameter of the extrudates. Each profile was acquired with 25 points resulting in a constant step of about $56 \mu \mathrm{m}$. Local measured concentrations were then processed using the method of the distance transform described elsewhere [32] to obtain the overall concentration of each element in the extrudate. The distribution coefficient was calculated as the ratio of the mean concentration along the extrudate to the overall concentration [33]. A distribution coefficient close to 1 stands for a uniform distribution of the element along the extrudate diameter. Otherwise, the coefficient will be higher than 1 , if the concentration is greater in the core than at the edges (so-called egg-yolk distribution); and lower than 1 if the concentration is greater at the edges than in the core (socalled egg-shell distribution).

Transmission electron microscopy (TEM) and high-angle annular dark-field scanning transmission electron microscopy (HAADF-STEM) observations were performed using a JEOL JEM $2100 \mathrm{~F}$ microscope operated at $200 \mathrm{kV}$. Samples were embedded in an epoxy resin, and thin slices (about $70 \mathrm{~nm}$ ) were cut by using an ultramicrotome and transferred onto a cooper grid covered by a carbon holey membrane. The MoS 2 crystallites observed in TEM were the ones parallel to the incident electron beam. An angle between the slab and the beam higher than $5^{\circ}$ leads to an interference between the incident and the reflected beam and the particle becomes invisible [34]. Therefore, only a small part of $\mathrm{MoS}_{2}$ crystallites are observed but this 
matches to a random sampling of crystallites observed and so results are representative of the whole population of $\mathrm{MoS}_{2}$ crystallites. At least 250 crystallites were measured to get hold of the slab length and stacking histograms.

X-ray photoelectron spectroscopy (XPS) was used to identify and quantify the chemical species existing in the transition metal sulphides samples. The measures were carried out in a ESCA KRATOS Axis Ultra spectrometer using a monochromatic source of Al, with an excitation energy of $1487 \mathrm{eV}$, an excitation power of $15 \mathrm{kV} \times 10 \mathrm{~mA}$ with a work function of 40,10 and $5 \mathrm{eV}$. The samples were prepared in a glove box under argon atmosphere. The sample was finely ground before being placed in the analysis chamber. During spectra acquisition a charge neutraliser was utilized. The spectra obtained were calibrated in relation to the contaminating carbon. The peaks of the chemical species were identified according to their binding energies [35,36]. The contribution of each species in an element was calculated by the ratio of each peak area to the total area of that element [37]. An example of spectrum deconvolution and species identification is provided in Supplementary Information, together with the deconvolution results. The atomic $\mathrm{Ni} / \mathrm{Mo}$ ratio of $\mathrm{MoS}_{2}$ slabs was calculated as the product of the bulk Ni/Mo ratio obtained by XRF and the fractions of $\mathrm{Ni}$ atoms involved in the NiMoS phase and of Mo atoms corresponding to $\mathrm{MoS}_{2}$.

$$
\left(\frac{N i}{M o}\right)_{\text {slabs }}=\left(\frac{N i}{M o}\right)_{b u l k} \times \frac{\% N i_{N i M o S}}{\% M o_{M o S_{2}}} \quad \text { Equation (1) }
$$

\subsection{Catalytic evaluation}

Cyclohexane hydroconversion was carried out in a high-throughput catalytic test unit with sixteen fixed-bed downflow reactors at 4.1 MPa. The operating conditions and catalyst granulometry were carefully chosen to ensure ideal plug-flow behaviour, according to the standard guidelines [38]. In particular, the shaped catalysts were grounded into 0.2-0.35 mm pellets before being loaded into reactors. The catalytic test was fully automated, with the operating conditions of the catalytic bed of each reaction being monitored individually. The liquid feedstock contained 93.5 to 94.0 wt.\% of cyclohexane, 6 wt.\% of dimethyldissulphide (DMDS), and 0 to $0.5 \mathrm{wt} . \%$ of aniline. This feed was mixed with hydrogen before entering the reactor and fully vaporized before reaching the catalyst bed. DMDS and aniline were entirely converted under testing conditions (according to GC analysis at reactor outlet) into methane and hydrogen sulphide and into cyclohexane and ammonia, respectively. The catalysts were sulphided at 673 $\mathrm{K}$ over $1 \mathrm{~h}$ (heating rate of $5 \mathrm{~K} \mathrm{~min}^{-1}$ ) in presence of the feed at a weight hourly space velocity (WSHV) of 3.2 gfeed $g_{\text {catalyst }}{ }^{-1} \mathrm{~h}^{-1}$.

The operating conditions of the three tests performed are summarized in Table 1. Fresh catalysts were loaded to perform each test. No sign of deactivation was observed during the 
stabilization of the first operating condition of each test. During the tests, the space velocity was kept constant and the parameter being evaluated (either temperature or $\mathrm{NH}_{3}$ partial pressure) was changed, according to the order shown in Table 1. Products were analysed on-line by two GC-FID instruments equipped with low polarity capillary columns. The outlet of each reactor was analysed at least three times to confirm that steady-state was reached. The results presented correspond to the average of two product analyses at steady-state conditions.

The $\mathrm{H}_{2}$ /cyclohexane ratio employed was lower in absence of $\mathrm{NH}_{3}$ than that in presence of $\mathrm{NH}_{3}$ in order to achieve the highest cyclohexane space velocity possible keeping thus conversion at level allowing the comparison between experiments (below $80 \%$ ). Due to the excess of $\mathrm{H}_{2}$ throughout the reactor, the effect of $\mathrm{H}_{2} /$ cyclohexane ratio was assumed to be restrained to a dilution effect. The activity was calculated as the apparent kinetic constant for first-order consumption of cyclohexane per catalyst mass per unit of time in an ideal plug-flow reactor, accounting thus for the effect of dilution in the partial pressure of cyclohexane (further details in $\mathrm{SI}$ ). The selectivity of a given product was calculated as the amount of carbon atoms from that product divided by total amount of carbon atoms in the products.

\section{Physico-chemical properties of materials}

\subsection{Shaped HUSY support}

The FAU framework type has a three dimensional pore structure with pore openings holding a minimum size of $0.74 \mathrm{~nm}$ [39]. The particular commercial sample of HUSY zeolite employed in this work has well-defined crystals of a few hundreds of nanometers in size and possesses both micro and mesopores, as previously disclosed [40]. The overall Si/Al molar ratio is of 17 and, according to ${ }^{27} \mathrm{AI}$ NMR measurements, the percentage of EFAL species is relatively low (13\%), [41]. This results in a concentration of $\mathrm{Al}^{\mathrm{IV}}\left(\mathrm{n}_{\mathrm{Al}}\right)$ around $820 \mu \mathrm{mol} \mathrm{g}{ }^{-1}$. As these aluminum atoms generate negatively charged oxygen atoms in zeolite frameworks [4], n $\mathrm{n}_{\mathrm{Al}}$ can be used as an estimation of the total concentration of Brønsted acid sites for zeolites in the protonic form.

The trilobe extrudate support was prepared by shaping the HUSY zeolite with a commercial boehmite. The composition of the shaped support after calcination is presented in Table 2. The zeolitic extrudates comprised roughly $83.5 \%$ of alumina and $16.5 \%$ of HUSY zeolite, based on the amount of silicon detected in shaped samples. In a previous study, the characterization of the shaped sample revealed full preservation of the zeolite properties in the extrudates, in particular the zeolite porosity and its Brønsted acidity [5]. Quantification of the Brønsted acid sites of shaped zeolite either by $\mathrm{NH}_{3}$-TPD or pyridine thermodesorption followed by FTIR is rather problematic. $\mathrm{NH}_{3}$-TPD is insensitive to the type of the acid site (Brønsted or Lewis). For FTIR, the contribution of the acid sites of the shaped zeolite is greatly reduced because of the dilution effect. It prevents proper quantification of the Brønsted acid sites [5]. These hurdles 
were overcome by using a specific model reaction sensitive to Brønsted acidity [5]. As full preservation of the catalytic activity of the Brønsted acid sites was observed for this support [5], the concentration of Brønsted sites in the extrudates can be thus directly estimated by that on the parent zeolite, taking into account the zeolite amount in the support. Concentration of Brønsted acid sites of the parent zeolite was considered equal to the concentration of $A^{\mathrm{IV}}$ deduced form ${ }^{27} \mathrm{Al}$ NMR and XRF results. The total concentration of Brønsted acid sites is thus expected to be around $135 \mu \mathrm{mol}$ gsupport $^{-1}$.

\subsection{NiMo-based catalysts}

\section{Metal composition and distribution}

Two NiMo catalysts with different Mo content were prepared in order to assess the impact of metal to acid sites ratio on the catalytic performances. The Mo contents selected were 12 and 16 wt.\%. The selection of the Ni/Mo atomic ratio was based on the reports in literature suggesting optimal hydrogenating activity in the 0.4-0.6 atomic range [42,43]. During the impregnation stage, a source of phosphor was added to promote the formation of heteropolymolybdates species which are more water soluble than the metal precursors. Considering the state-of-the-art, the P/Mo atomic ratio was fixed at 0.48 [44]. The composition of $\mathrm{NiMo} /\left(\mathrm{HUSY}+\mathrm{Al}_{2} \mathrm{O}_{3}\right)$ samples as measured by $\mathrm{XRF}$ is presented in Table 3 . The content of Mo as well as the Ni/Mo and P/Mo ratios were analogous to the targeted values. The samples will be hereon distinguished by their Mo content, i.e. the sample designated $12 \% \mathrm{NiMo} /\left(\mathrm{HUSY}+\mathrm{Al}_{2} \mathrm{O}_{3}\right)$ corresponds to the one with a Mo content of $12.0 \mathrm{wt} . \%$. It is worth mentioning that the total amount of $\mathrm{Ni}$, Mo and $\mathrm{P}$ oxides corresponded to 20 to $40 \mathrm{wt} . \%$ of the catalyst composition after calcination. This explains the decreasing percentage of zeolite on the calcined catalysts with increasing metals content (Table 3). Thereby, the concentration of Brønsted acid sites in the final catalyst was thus considerably lower than on the shaped support.

In Fig. 1, micro and mesoporous volume of NiMoS-based samples are compared to those of shaped supports. The volume of micropores on the support was retained after NiMoP introduction whereas that of mesopores decreased. The loss ranged from 10 to $30 \%$ of the initial mesopores volume, increasing along with the amount of Mo introduced. As only the mesopores are affected by NiMoP introduction, one may assume that the metal oxides were deposed mainly in the alumina and/or the mesopores of HUSY zeolite. More importantly, the preservation of the microporous volume pointed to a full accessibility to the corresponding acidic sites and an unchanged zeolite structure.

The evaluation of metal distribution in extrudates was carried out by Electron Probe Micro Analysis (EPMA) over the calcined samples. The distribution coefficients, which measure the uniformity of an element distribution along the diameter of extrudates (vide section 2.2), are 
provided in Table 3. The distribution coefficients were close to 1 in all cases revealing a uniform distribution of $\mathrm{Ni}$ and $\mathrm{Mo}$ along the extrudates diameter. The distribution coefficient for silicon was also measured for the support (0.98) confirming, hence, the uniform distribution of the zeolite within the alumina reported previously [5].

\section{Sulphided phase}

The morphology of $\mathrm{MoS}_{2}$ nanocrystallites was studied by Transmission Electron Microscopy (TEM). The micrographs of $12 \% \mathrm{NiMoS} /\left(\mathrm{HUSY}+\mathrm{Al}_{2} \mathrm{O}_{3}\right)$ focusing on the alumina support with different magnifications are presented in Fig. 2. The platelets of alumina appeared homogeneous in morphology with a length within the 5-20 nm range. The $\mathrm{MoS}_{2}$ slabs correspond to the agglomerates of alternate black and white fringes which seemed to be homogeneously dispersed on the alumina (Fig. 2b). Both straight and curved slabs were observed in the sulphided samples (upper arrows in Fig. 2b). This latter type of slab morphology has already been reported in literature [45-47]. Both $\mathrm{NiMoS} /\left(\mathrm{HUSY}+\mathrm{Al}_{2} \mathrm{O}_{3}\right)$ samples had a mean slab length of ca. $3.5 \mathrm{~nm}$ (Table 4). It is however noteworthy that the distribution of slab length populations did not match a normal distribution (Fig. S1). The number of dark fringes enabled the estimation of the number of $\mathrm{MoS}_{2}$ slabs stacked in each crystallite revealing an average stacking of 2.0 for both samples.

According to literature, the active sites for hydrogenation/dehydrogenation reactions in NiMoSbased catalysts are $\mathrm{MoS}_{2}$ sites promoted with $\mathrm{Ni}$ (so-called mixed sites) [43]. The X-ray photoelectron spectroscopy (XPS) was thus used to quantify such species and its atomic composition through the spectra of molybdenum and nickel $[36,37,48]$. The main results of XPS measurements over NiMo sulphided samples are summarized in Table 4 (vide Section 2.2 for further experimental details). About $70 \%$ of the molybdenum atoms were sulphided (into $\mathrm{MoS}_{2}$ slabs) which might include both promoted and unpromoted species. The amount of $\mathrm{MoS}_{2}$ does not provide hence an adequate quantification of the active sites. Instead, one might focus on the $\mathrm{Ni}$ atoms promoting the $\mathrm{MoS}_{2}$ edge sites. The nickel involved in mixed sites corresponded to roughly half of the whole $\mathrm{Ni}$ loaded (Table 4 ) which is in line with literature reports on NiMoSbased catalysts [43]. The atomic Ni/Mo ratio of $\mathrm{MoS}_{2}$ slabs was about 0.29 (Table 4) which is somewhat lower than the bulk Ni/Mo ratio (Table 3). This can be easily explained as $\mathrm{MoS}_{2}$ phase corresponded to $75 \%$ of all Mo whereas only $50 \%$ of the whole Ni was in NiMoS phase (Table 4). The remaining nickel was in either the oxide ( $\mathrm{NiO})$ or the sulphide form $\left(\mathrm{Ni}_{3} \mathrm{~S}_{2}\right.$ or $\left.\mathrm{NiS}\right)$. Lastly, it is worth mentioning that no impact of the total metal loading on the characteristics of the mixed phase could be discerned.

The amount of mixed sites formed per $\mathrm{MoS}_{2}$ slab depend on the actual Ni/Mo ratio and on the size of the slab [43]. For samples with analogous (Ni/Mo)slabs and comparable slab length, the amount of mixed sites existing in the samples is thus proportional to the amount of $\mathrm{Ni}$ engaged in NiMoS phase. Furthermore, for promotion levels below the maximal decoration of $\mathrm{MoS}_{2}$ 
slabs, it seems reasonable to assume that each $\mathrm{Ni}$ atom promotes a Mo atom in the edges of $\mathrm{MoS}_{2}$ slabs. For slabs in the same range of length than the ones considered here, the Ni/Mo atomic ratio leading to optimal decoration of the $\mathrm{MoS}_{2}$ slabs is 0.5 [43]. The NiMoS-based samples at stake match reasonably well all the three criteria and the amount of $\mathrm{Ni}$ engaged in NiMoS phase was thus used to estimate the number of mixed sites. To do so, we have taken into account the weight fraction of $\mathrm{Ni}$ in the samples measured by $\operatorname{XRF}\left(x_{N i}\right)$ along with the fraction of $\mathrm{Ni}$ engaged in the NiMoS sites $\left(x_{N i_{N i M O S}}\right)$ as estimated by XPS and the atomic mass (AM) of nickel (Eq. 9.2).

$$
n_{N i M o S}=\frac{x_{N i} \times x_{N i_{N i M O S}}}{A M(N i)} \quad \text { Equation (2) }
$$

The concentration of NiMoS sites (nNimos) was in the $0.2-0.4 \mathrm{mmol} \mathrm{g}^{-1}$ range (Table 4). The number of NiMoS sites increased along with metal content, as expected. The amount of Mo in the NiMoS site corresponded, in average, to $15 \%$ of the overall Mo deposed on the catalyst, revealing that most part of molybdenum would not participate in the intended reactions. This is common to all $\mathrm{MoS}_{2}$ promoted catalysts as only the Mo-edge sites of the slabs can be promoted and thus active in catalysis. Taking into account $\mathrm{n}_{\mathrm{Nimos}}$ and $\mathrm{n}_{\mathrm{Al}}$, the metal to acid sites molar ratio could be hence calculated for the NiMoS/(HUSY $\left.+\mathrm{Al}_{2} \mathrm{O}_{3}\right)$ samples. The two catalysts studied held hence distinct metal to acid sites molar ratio in line with the different metal loading (Table 4).

\section{Hydroisomerization of cyclohexane in presence and absence of ammonia}

The hydroconversion of cyclohexane is expected to proceed through a bifunctional classical mechanism as the one commonly established for alkanes (Fig. 3) [2]. The cyclohexane is dehydrogenated in metallic sites and the naphthenic intermediate diffuses to the acidic function where it is protonated by a Brønsted acid site [49,50]. The resulting carbenium ion can then undergo either isomerization or cracking steps. The first step is the hydroisomerization (HI) of cyclohexane into methylcyclopentane. The reaction can proceed through $\beta$-scission resulting in the cyclopentane ring opening (R.O.). The formed $n$-hexane can be then isomerized into methyl-pentane which can further react, giving raise to cracking products (mostly propane).

\subsection{Reaction in absence of ammonia}

The $\mathrm{NiMoS} /\left(\mathrm{HUSY}+\mathrm{Al}_{2} \mathrm{O}_{3}\right)$ catalysts were firstly tested in the conversion of a $\mathrm{NH}_{3}$-free feedstock. For reaction temperatures within $580-610 \mathrm{~K}$, the cyclohexane conversion was in the 30-65\% range for both catalysts (Fig. 4a). The increasing Mo content led only to a marginal increase in the conversion level. The product selectivity was studied at ca. 50\% conversion (Fig. 
4b). The selectivity toward hydroisomerization reaction was superior to $90 \%$. In other words, under the chosen conditions, the production of by-products was restrained, leading hence to a main product, methylcyclopentane. In addition, the product selectivity was similar irrespectively of the Mo loading. As referred in the Introduction, according to the classical bifunctional mechanism [6], both the turnover frequency per Brønsted acid site and the selectivity towards isomerization will attain their maximal value for high metal to acid sites ratios, being thus almost insensitive to further changes in this ratio $[7,8]$. In this sense, the low impact of Mo loading on catalytic behaviour indicates that the NiMoS sites are in sufficient amount to feed all the acid sites with intermediate naphthenic molecules, i.e. the catalyst is well-balanced.

\subsection{Reaction in the presence of ammonia}

The role of $\mathrm{NH}_{3}$ in the inhibiting of Brønsted sites was firstly studied by varying the content of $\mathrm{NH}_{3}$ in the feedstock. As the nitrogen content in VGOs ranges from 300 to 2000 wt. ppm [51], the reference feedstock contained 750 wt. ppm of nitrogen. At the working total pressure (4.1 $\mathrm{MPa}$ ), this resulted in a $\mathrm{NH}_{3}$ partial pressure of $2.8 \mathrm{kPa}$ (through complete decomposition of 0.5 wt.\% of aniline in the feedstock). With the purpose of studying the impact of lower partial pressures, the nitrogen content was decreased from $750 \mathrm{ppm}$ (reference condition) to 150 and $50 \mathrm{ppm}$ leading to $\mathrm{NH}_{3}$ partial pressures of $2.8,0.6$ and $0.2 \mathrm{kPa}$, respectively. The catalysts were tested at longer contact times of reactant (4-fold) and higher reaction temperatures (623 vs. $583 \mathrm{~K}$ ) as compared to the $\mathrm{NH}_{3}$-free conditions. Still, the conversion levels were superior in absence of $\mathrm{NH}_{3}(30-65 \%)$ as compared to those (3-10\%) using a $\mathrm{NH}_{3}$ partial pressure of 2.8 $\mathrm{kPa}$ (Fig. 5a). These first results confirmed thus a tremendous loss of the catalytic activity in presence of $\mathrm{NH}_{3}$.

Fig. 5a depicts the evolution of cyclohexane conversion with $\mathrm{NH}_{3}$ partial pressure. For both catalysts, the conversion increased markedly with decreasing $\mathrm{NH}_{3}$ pressures. The selectivity towards hydroisomerization products was about $95 \%$. Once again, neither the catalytic activity nor the product selectivity (Fig. 5b) were influenced by the Mo content indicating that the acidcatalysed reactions were rate-limiting irrespectively of the $\mathrm{NH}_{3}$ pressure. Furthermore, the product selectivity did not depend on $\mathrm{NH}_{3}$ pressure (Fig. $4 \mathrm{~b}$ and Fig. 5b) sustaining the hypothesis that the catalysts were well-balanced over the whole experimental conditions. This implies that, regardless of the operating conditions, the reaction mechanism should have been analogous, as well, and, thereby, the kinetics. In short, the same kinetics can thus be assumed for all experiments.

As the reactions in absence and presence of $\mathrm{NH}_{3}$ were performed at different temperatures, the catalytic activities are compared through an Arrhenius plot. The catalytic activity was calculated as the apparent constant for first-order kinetics on both cyclohexane $[8,52,53]$ and Brønsted $[7,8]$, as typically performed for the hydroconversion of $n$-paraffins, due to the similarity of reaction mechanisms. The comprehensive deduction of corresponding equation is shown in 
Supporting Information. The Arrhenius's plot is depicted in Fig. 6 for cyclohexane conversion either in the absence or presence of $\mathrm{NH}_{3}(2.8 \mathrm{kPa}$ ). Without ammonia (open symbols), conversion took place at lower temperatures but catalytic activity was, even though, superior to that obtained in presence of $\mathrm{NH}_{3}$. There was thus a great reduction of catalytic activity when $\mathrm{NH}_{3}$ was fed to the reaction medium, as previously suggested. Moreover, activation energies were also significantly different: in absence of $\mathrm{NH}_{3}$ it amounted to $142 \mathrm{~kJ} \mathrm{~mol}^{-1}$, raising to $219 \mathrm{~kJ}$ mol-1 in presence of $\mathrm{NH}_{3}$. As the product selectivity was not affected by $\mathrm{NH}_{3}$, the reaction pathway should be similar and so the apparent activation energy for the hydroconversion of cyclohexane. The difference on the apparent activation energy can be hence attributed to the enthalpy of desorption of $\mathrm{NH}_{3}$ on the Brønsted acid sites, as the desorption phenomenon is endothermic. Therefore, as the reaction temperature increases, more acid sites are available to catalyse the cyclohexane hydroconversion. This increased activation energy has already been predicted in literature for the hydroconversion of $n$-hexadecane: in presence of nitrogencontaining inhibitor, the apparent activation energy was estimated to increase from 140 to 250 $\mathrm{kJ} \mathrm{mol}^{-1}$ [54]. Our results agree, hence, with those in literature and the increased activation energy confirms the significant amount of Brønsted sites inhibited by ammonia.

\section{Quantification of the available Brønsted acid sites in the presence of ammonia}

On the one hand, as ammonia is strongly adsorbed on the Brønsted sites, one may assume that the adsorption of $\mathrm{NH}_{3}$ is at the equilibrium. Moreover, as naphtenes are much weaker bases, competition between the naphthenic intermediates and $\mathrm{NH}_{3}$ is rather unlikely. Therefore, naphthenes will be only adsorbed (and converted) on the non-inhibited Brønsted sites. On the other hand, reports in literature suggest that the turnover frequency over protonic sites depends mainly on the confinement of reactant molecules $[8,55]$ and so the presence of $\mathrm{NH}_{3}$ is not expected to affect it. Accordingly, as acid-catalysed reactions appeared to be rate-limiting regardless of $\mathrm{NH}_{3}$ pressure, the turnover frequency over the Brønsted sites should have been constant [8]. Assuming that the partial order of both cyclohexane and vacant Brønsted sites in the rate of cylclohexane conversion, the activity should be directly proportional to the number of available Brønsted sites and partial pressure in cyclohexane at reactor inlet. The fraction of vacant (i.e. non-inhibited by $\left.\mathrm{NH}_{3}\right)$ Brønsted sites $\left(\psi_{\mathrm{v}}\right)$ at given partial pressure of $\mathrm{NH}_{3}$ and temperature can be then estimated by the ratio of the activity at that pressure of $\mathrm{NH}_{3}$ to the activity in absence of $\mathrm{NH}_{3}$ at that same temperature, taking into account possible differences in the partial pressure of reactant (Eq. 3). The step-by-step deduction of Eq. 3 is provided as Supporting Information. 
$\Psi_{V}\left(T, P_{N_{3}}\right)=\frac{n_{A l}^{\text {vacant }}\left(T, P_{N_{3}}\right)}{n_{A l}} \Rightarrow \psi_{V}\left(T, P_{N_{3}}\right)=\frac{\operatorname{Activity}\left(T, P_{C C_{6}, a}^{0}, P_{N H_{3}}\right)}{\operatorname{Activity}\left(T, P_{C C_{6}, b}^{0}, 0\right)} \frac{P_{C C_{6}, b}^{0}}{P_{C C_{6}, a}^{0}} \quad$ Equation (3)

The concentration of vacant acid sites ( $\mathrm{n}_{\mathrm{Al}} \mathrm{v}^{\mathrm{vacant}}$ ) at a given temperature and $\mathrm{NH}_{3}$ partial pressure corresponds to the fraction of vacant sites at that temperature and pressure times the overall concentration of sites (i.e. $\mathrm{n}_{\mathrm{Al}}$ ) - Eq. (4). The overall concentration of Brønsted sites in the HUSY zeolite is around $820 \mu \mathrm{mol}$ gzeolite $^{-1}$ (see Section 3.1).

$$
n_{A l}^{\text {vacant }}\left(T, P_{N_{3}}\right)=\psi_{V}\left(T, P_{N H_{3}}\right) \times n_{A l}
$$

Equation (4)

\subsection{Partial pressure effect}

The fractions of vacant Brønsted sites in the NiMoS/(HUSY $\left.+\mathrm{Al}_{2} \mathrm{O}_{3}\right)$ were estimated at $623 \mathrm{~K}$. This temperature is within the range of typical temperatures for industrial hydrocracking reactors [1]. To do so, the catalytic activity in absence of $\mathrm{NH}_{3}$ at $623 \mathrm{~K}$ was estimated by Arrhenius' equation (Fig. 6). The estimated fractions of vacant (i.e. non- inhibited by $\mathrm{NH}_{3}$ ) Brønsted sites were plotted as a function of $\mathrm{NH}_{3}$ pressure in Fig. 7. For a $\mathrm{NH}_{3}$ pressure of $0.2 \mathrm{kPa}$, only $2 \%$ of the whole Brønsted sites were available for reaction. Increasing the $\mathrm{NH}_{3}$ pressure till $2.8 \mathrm{kPa}$, led to fractions of vacant sites as low as $0.6 \%$ and consequently lower activities. In other words, the apparent kinetic constant for cyclohexane conversion in absence of $\mathrm{NH}_{3}$ was more than 150 -fold higher that in presence of $2.8 \mathrm{kPa}$ of $\mathrm{NH}_{3}$.

Results herein reveal that, at reaction conditions, only about $0.6 \%$ of whole population of Brønsted sites was available for the cyclohexane hydroconversion. Reports in literature point to $10 \%$ of vacant Brønsted sites for $\mathrm{HUSY}$ at $\mathrm{NH}_{3}$ pressure of $1 \mathrm{kPa}$ and $663 \mathrm{~K}$, in $n-\mathrm{C}_{7}$ hydroconversion [28]. Our results are somehow coherent with those as $\mathrm{NH}_{3}$ adsorption occurred roughly in the same range of partial pressures. The higher temperature in this latter case is likely at the origin of the higher fraction of vacant sites. Furthermore, as $98 \%$ of the sites were inhibited at $0.2 \mathrm{kPa}$ of $\mathrm{NH}_{3}$, the most part of Brønsted sites were inhibited for ammonia pressures lower than $0.2 \mathrm{kPa}$, i.e. $50 \mathrm{ppm}$ of $\mathrm{NH}_{3}$ at $4.1 \mathrm{MPa}$ and $\mathrm{H}_{2} / \mathrm{HC}$ molar ratio of 4.5 . In the same sense, another study, focused on the influence of weakly basic, but highly refractory nitrogen compounds, reports losses in catalytic hydrocracking activity for nitrogen contents in hydrotreated VGO of around 5 ppm [56].

In order to roughly estimate the range of partial pressures in which $\mathrm{NH}_{3}$ adsorption took place, the adsorption isotherm of $\mathrm{NH}_{3}$ has to be calculated. Results suggest that adsorption of $\mathrm{NH}_{3}$ was not directly proportional to $\mathrm{NH}_{3}$ partial pressure. Instead, most of the sites were inhibited at very low partial pressures. These results can be thus expected to be fairly well represented by a Langmuir-type isotherm, as it is, indeed, typically the case in literature for the adsorption of $\mathrm{NH}_{3}$ in zeolites [57-59]. 
The isotherm of $\mathrm{NH}_{3}$ adsorption on the Brønsted sites of HUSY zeolite at $623 \mathrm{~K}$ was then regressed assuming a Langmuir-type isotherm (Fig. 8). As one may have anticipated by the previous results, for partial pressures in the 0.1-3.0 kPa range, Brønsted sites were nearly saturated by $\mathrm{NH}_{3}$ molecules. According to the calculated isotherm, a significant amount (20 to $80 \%$ ) of the Brønsted acid sites would still be inhibited for partial pressures between 0.001 and $0.01 \mathrm{kPa}$. These results should be considered very cautiously, as the experimental points correspond only to upper part of the calculated isotherm. Nonetheless, one may sustain, with a considerable degree of certainty, that marginal inhibition of the Brønsted acid sites would only occur for ammonia partial pressures some orders of magnitude lower than the ones employed during this work and prevailing in hydrocracking reactors.

It is worth mentioning that carrying out catalytic tests in these range of partial pressures is not straightforward at the bench scale because the $\mathrm{NH}_{3}$ source molecule (in our case aniline, see section 2.3) has to be significantly diluted in the liquid feed. This implies small weight fractions which cannot be measured as they are below the detection limits of typical routine analysis (e.g. Gas Chromatography). For instance, for a partial pressure of $0.01 \mathrm{kPa}$, only 20 wt. ppm of aniline in the feedstock are required.

The concentration of Bronsted vacant sites ( $\mathrm{n}_{\mathrm{Al}}{ }^{\text {vacant}}$ ) at $623 \mathrm{~K}$ for each $\mathrm{NH}_{3}$ partial pressure was calculated according to Eq. (4). The reduction of $\mathrm{NH}_{3}$ pressure from 2.8 to $0.2 \mathrm{kPa}$ led to a 3fold increase on the concentration of vacant Brønsted sites (Fig. 9a). Even if this increase in $\mathrm{n}_{\mathrm{Al}}{ }^{\text {vacant }}$ is important in terms of activity, it is relatively small comparing to the drop in $\mathrm{NH}_{3}$ partial pressure: 14-fold. This means that, in such conditions, small variations in the $\mathrm{NH}_{3}$ partial pressure will barely affect the concentration of vacant sites. This relative insensitivity of $n_{A l}$ vacant to $\mathrm{NH}_{3}$ partial pressure agrees with the saturation of the Brønsted sites disclosed in the $\mathrm{NH}_{3}$ Langmuir-type isotherm (Fig. 9).

\subsection{Temperature effect}

Fig. 9b) depicts the concentration of vacant sites in the HUSY zeolite under $2.8 \mathrm{kPa}$ of $\mathrm{NH}_{3}$ as function of the reaction temperature. From 600 to $640 \mathrm{~K}$, the concentration of vacant Brønsted sites can be increased from 2 to $6 \mu \mathrm{mol} \mathrm{g}_{\text {zeolite }}{ }^{-1}$. This increase is in agreement with the endothermicity of desorption phenomena and has been previously suggested in literature [28]. Comparing the impact of both operating parameters, a similar relative increase in nalvant (3fold) was achieved by either raising the temperature by $40 \mathrm{~K}$ or by a 14 -fold reduction of the $\mathrm{NH}_{3}$ partial pressure. Therefore, an increase in the reaction temperature can be equivalent to a great reduction in $\mathrm{NH}_{3}$ partial pressure.

Lastly, it is worth mentioning that the typical Brønsted sites concentration over protonic zeolite ranges from 100 to $1500 \mu \mathrm{mol}$ gzeolite $^{-1}$, depending on the framework and the Si/Al ratio [12]. In presence of $\mathrm{NH}_{3}$, concentrations of vacant sites in zeolite were in the $3-15 \mu \mathrm{mol}$ gzeolite $^{-1}$ range. 
The estimations herein point hence to a much lower concentration of vacant Brønsted sites in inhibited HUSY zeolite as compared to non-inhibited zeolites, even for very high Si/Al ratios (e.g. HSZM-5 with a framework Si/Al of 120 has $110 \mu \mathrm{mol}$ gzeolite $^{-1}$ Brønsted acid sites [24]). Therefore, in presence of $\mathrm{NH}_{3}$, the Brønsted acidity is irremediably truncated and the HUSY zeolite holds a very weak acidity as compared to non-inhibited zeolites. As a consequence, for bifunctional catalysts, the inhibition of acid sites will substantially modify the metal to acid sites ratio (Table 5). It is known that the metal to acid sites ratio can greatly impact the performances of a bifunctional catalyst, especially when the catalyst is not well balanced (i.e. there is a lack of metal sites as compared to acid sites [5-9]). In the present case of study, no visible impact was observed but the metal-acid balance requirements strongly depend on the operating conditions and on the feedstock [60]. Therefore, for reaction requiring greater metal to acid sites ratio, the inhibition of a great part of the acid sites will most likely impact the balance between metal and acid sites. As high metal to acid sites ratio maximise the selectivity and resistance to deactivation of bifunctional catalysts [6-8], the presence of $\mathrm{NH}_{3}$ is expected to lead to an enhanced catalytic performance in this respect.

As referred in the Introduction, controlling the inhibition of acid sites by ammonia in industrial catalysts is vital to achieve an optimal balance between the loss of activity and the enhanced selectivity. In industrial practice, this control can be achieved either by increasing the reaction temperature or removing ammonia, as in the case of two stage hydrocracking process configuration [1]. According to the disclosed results, the amount of available acid sites is significantly more sensitive to changes in the reaction temperature than on $\mathrm{NH}_{3}$ partial pressure, due to the nearly saturation of acid sites with $\mathrm{NH}_{3}$. Moreover, from a practical point of view, modulating the available acid sites via temperature control is much faster and less costly, as no additional equipment is required. Therefore, this study points towards a preferential utilization of the temperature to control the concentration of Bronsted vacant sites in hydroconversion bifunctional catalysts. As a matter of fact, this is implicitly the choice made when one selects a single-stage over a two-stage hydrocracking process.

\section{Conclusion}

The vacuum gas oil (VGO) used in hydrocracking process contains nitrogen-containing base molecules which are known to inhibit the Brønsted acid sites of zeolites present in hydrocracking catalysts. In this work, we aimed to take a step forward and quantify the number of acid sites inhibited by $\mathrm{NH}_{3}$ in typical hydrocracking reaction conditions. This quantification was achieved by testing the bifunctional catalysts based on HUSY zeolite in cyclohexane hydroconversion in absence and presence of ammonia and ensuring that catalysts were wellbalanced throughout all the operating conditions.

Under the chosen hydroconversion conditions, the fraction of inhibited Brønsted sites was superior to $98 \%$ due to the adsorption of ammonia, i.e. the Brønsted sites are nearly saturated 
by $\mathrm{NH}_{3}$ molecules. Considering a constant turnover frequency per available acid site, the results herein hint at a reduction of the hydroconversion activity by 150 -fold comparing to catalysts working in the absence of ammonia. Therefore, substantial gains in terms of activity can be achieved by mitigating the inhibition of acid sites by ammonia in hydroconversion reaction.

Significant reduction in the $\mathrm{NH}_{3}$ content of the feedstock caused rather moderate variations on the number of available Brønsted sites. Moreover, inhibition of the Brønsted acid sites would only be negligible for ammonia partial pressures some orders of magnitude lower than those existing in industrial conditions. Conversely, a temperature raise from 600 to $640 \mathrm{~K}$ triplicated the fraction of vacant Brønsted sites due to the significant endothermicity of ammonia desorption. The inhibiting effect of ammonia can be therefore easily modulated by the reaction temperature and optimized by quantifying the change in available acid sites with temperature.

As the inhibition by $\mathrm{NH}_{3}$ depends on the zeolite structure and composition (via the number and strength of acid sites), the effect of partial pressures and temperature can be expected to be zeolite-dependent as well. Therefore, quantifying the amount of acid sites in different catalysts is expected to enhance the understanding of hydrocracking catalysts behaviour in industriallyrelevant conditions and bridge the gap between laboratory studies and industrial practice.

In summary, the presence of $\mathrm{NH}_{3}$ in the order of some thousands of Pascal $(\mathrm{kPa})$, as in hydrocracking industrial reactors, can result in an extensive reduction of the amount of available Brønsted acid sites and consequently of the catalytic activity. The quantification of such effect under reactions conditions is possible through the use of simple reaction models, as cyclohexane hydroconversion. In the particular case of nearly saturated acid sites, the temperature is the most straightforward operating variable to mitigate the inhibition by nitrogencontaining compounds.

\section{Acknowledgments}

The authors would like to thank S. Cremer and B. Guichard for the catalytic tests; P. Lecour and S. Ahal-El Ahrache for the work on XPS; V. Lefebvre, Y. Blouet, F. Fillali and A.-S. Gay for the work on electron microscopy techniques; and $G$. Pirngruber for the fruitful discussions. Fundação para a Ciência e Tecnologia is acknowledge for financial support, through CQE (Project UID/QUI/00100/2013) and PhD grant (SFRH/BD/87927/2012).

\section{References}

[1] F. Bertoncini, A. Bonduelle-Skrzypczak, J. Francis, E. Guillon, in: H. Toulhoat, P. Raybaud (Eds.), Catalysis by Transition Metal Sulphides, Ed. Technip, Paris, 2013, pp. 609-677.

[2] J. Weitkamp, ChemCatChem 4 (2012) 292-306. 
[3] E.T.C. Vogt, G.T. Whiting, A. Dutta Chowdhury, B.M. Weckhuysen, in: F. C. Jentoft (Ed.), Advances in Catalysis 58, Academic Press, 2015, pp. 143-314.

[4] A. Primo, H. Garcia, Chem. Soc. Rev. 43 (2014) 7548-7561.

[5] P.S.F. Mendes, J.M. Silva, M.F. Ribeiro, A. Daudin, C. Bouchy, J. Ind. Eng. Chem. 62 (2018) 72-83.

[6] H.L. Coonradt, W.E. Garwood, Ind. Eng. Chem. Process Des. Dev. 3 (1964) 38-45.

[7] F. Alvarez, F.R. Ribeiro, G. Perot, C. Thomazeau, M. Guisnet, J. Catal. 162 (1996) 179189.

[8] P.S.F. Mendes, J.M. Silva, M.F. Ribeiro, P. Duchêne, A. Daudin, C. Bouchy, AIChE J. 63 (2017) 2864-2875.

[9] T.F. Degnan, C.R. Kennedy, AIChE J. 39 (1993) 607-614.

[10] E. Gutierrez-Acebo, C. Leroux, C. Chizallet, Y. Schuurman, C. Bouchy, ACS Catal. 8 (2018) 6035-6046.

[11] M. Guisnet, Catal. Today 218 (2013) 123-134.

[12] P.S.F. Mendes, F.M. Mota, J.M. Silva, M.F. Ribeiro, A. Daudin, C. Bouchy, Catal. Sci. Technol. 7 (2017) 1095-1107.

[13] C. Bouchy, G. Hastoy, E. Guillon, J.A. Martens, Oil Gas Sci. Technol. 64 (2009) 91-112.

[14] J.A. Martens, M. Tielen, P.A. Jacobs, in: H.G. Karge, J. Weitkamp (Eds.) Studies in Surface Science and Catalysis 46, Elsevier, 1989, Amsterdam, pp. 49-60.

[15] J.W. Thybaut, I.R. Choudhury, J.F. Denayer, G.V. Baron, P.A. Jacobs, J.A. Martens, G.B. Marin, Top. Catal. 52 (2009) 1251-1260.

[16] V.M. Akhmedov, S.H. Al-Khowaiter, Catal. Rev. 49 (2007) 33-139.

[17] S.M. Csicsery, Zeolites 4 (1984) 202-213.

[18] W.M. Zhang, P.G. Smirniotis, J. Catal. 182 (1999) 400-416.

[19] C.R. Marcilly, Top. Catal. 13 (2000) 357-366.

[20] A. Chica, A. Corma, Chem. Ing. Tech. 79 (2007) 857-870. 
[21] C.H. Bartholomew, Appl. Catal. A 212 (2001) 17-60.

[22] M. Argyle, C. Bartholomew, Catalysts 5 (2015) 145-269.

[23] M. Sau, K. Basak, U. Manna, M. Santra, R.P. Verma, Catal. Today 109 (2005) 112-119.

[24] F. Ribeiro, C. Marcilly, M. Guisnet, J. Catal. 78 (1982) 267-274.

[25] L.B. Galperin, Appl. Catal. A 209 (2001) 257-268.

[26] S.-W. Lee, S.-K. Ihm, Fuel 134 (2014) 237-243.

[27] S. Mignard, O. Béroudiaux, C.R. Acad. Sci., Ser. Ilb: Mec., Phys., Chim., Astron. 325 (1997) 271-278.

[28] P. Dufresne, A. Quesada, S. Mignard, in: D.L. Trimm, S. Akashah, M. Absi-Halabi and A. Bishara (Eds.), Studies in Surface Science and Catalysis 53, Elsevier, 1989, Amsterdam, pp. 301-315.

[29] M. Kobayashi, S. Togawa, K. Ishida, J. Jpn. Pet. Inst. 50 (2007) 44-52.

[30] G. Leofanti, M. Padovan, G. Tozzola, B. Venturelli, Catal. Today, 41 (1998) 207-219.

[31] L. Sorbier, E. Rosenberg, C. Merlet, Microsc. Microanal. 10 (2004) 745-752.

[32] L. Sorbier, F. Bazer-Bachi, Y. Blouet, M. Moreaud, V. Moizan-Basle, Microsc. Microanal. 22 (2016) 422-431.

[33] L. Sorbier, in: H. Toulhoat, P. Raybaud (Eds.), Catalysis by Transition Metal Sulphides, Ed. Technip, Paris, 2013, pp. 407-411.

[34] C. Geantet, L. Sorbier, in: H. Toulhoat, P. Raybaud (Eds.), Catalysis by Transition Metal Sulphides, Ed. Technip, Paris, 2013, pp. 434-453.

[35] J.F. Moulder, W.F. Stickle, P.E. Sobol, in: J. Chastain, R. C. King Jr. (Eds.), Handbook of X-ray Photoelectron Spectroscopy, Physical Electronics Division, Minnesota, 1979.

[36] A.D. Gandubert, C. Legens, D. Guillaume, S. Rebours, E. Payen, Oil Gas Sci. Technol. 62 (2007) 79-89.

[37] K. Marchand, C. Legens, D. Guillaume, P. Raybaud, Oil Gas Sci. Technol. 64 (2009) 719730. 
[38] J. Perez-Ramirez, R. J. Berger, G. Mul, F. Kapteijn, J. A. Moulijn, Catal. Today 60 (2000) 93-109.

[39] L.B. McCusker, C. Baerlocher, in: J. Cejka, H. VanBekkum (Eds.), Zeolites and Ordered Mesoporous Materials: Progress and Prospects, Elsevier, Amsterdam, 2005, pp. 41-64.

[40] P.S.F. Mendes, A.-L. Taleb, A.-S. Gay, A. Daudin, C. Bouchy, J.M. Silva, J. Mater. Chem. A 5 (2017) 16822-16833.

[41] P.S.F. Mendes, G. Lapisardi, C. Bouchy, M. Rivallan, J.M. Silva, M.F. Ribeiro, Appl. Catal. A 504 (2015) 17-28.

[42] P. Grange, Catalysis Reviews 21 (1980) 135-181.

[43] C. Legens, P. Raybaud, in: H. Toulhoat, P. Raybaud (Eds.), Catalysis by Transition Metal Sulphides, Ed. Technip, Paris, 2013, pp. 259-300.

[44] C. Lamonier, E. Payen, in: H. Toulhoat, P. Raybaud (Eds.), Catalysis by Transition Metal Sulphides, Ed. Technip, Paris, 2013, pp. 151-181.

[45] A.K. Datye, S. Srinivasan, L.F. Allard, C.H.F. Peden, J.R. Brenner, L.T. Thompson, J. Catal. 158 (1996) 205-216.

[46] Y. Iwata, Y. Araki, K. Honna, Y. Miki, K. Sato, H. Shimada, Catal. Today 65 (2001) 335341.

[47] P. Afanasiev, C.R. Chim. 11 (2008) 159-182.

[48] A.-F. Lamic, A. Daudin, S. Brunet, C. Legens, C. Bouchy, E. Devers, Appl. Catal. A 344 (2008) 198-204.

[49] M.G. Lazarraga, A. Voorhies, Ind. Eng. Chem. Prod. Res. Dev. 12 (1973) 194-198.

[50] M. Chow, S.H. Park, W.M.H. Sachtler, Appl. Catal. 19 (1985) 349-364.

[51] C. Marcilly, Acido-basic catalysis, Ed. Technip, Paris, 2005.

[52] M.J. Girgis, Y.P. Tsao, Ind. Eng. Chem. Res. 35 (1996) 386-396.

[53] V. Calemma, S. Peratello, C. Perego, Appl. Catal. A 190 (2000) 207-218. 
[54] R.T. Hanlon, C.R. Kennedy, R.A. Ware, S.S. Wong, in: L. Guczi, F. Solymosi, P. Tétényi (Eds.), Studies in Surface Science and Catalysis 75, Elsevier, 1993, Amsterdam, pp. 2423-2426.

[55] E.G. Derouane, J. Mol. Catal. A: Chem. 134 (1998) 29-45.

[56] C.M. Celis-Cornejo, D.J. Pérez-Martínez, J.A. Orrego-Ruiz, V. G. Baldovino-Medrano, Energy Fuels, 32 (2018) 8715-8726.

[57] M. Niwa, N. Katada, M. Sawa, Y. Murakami, J. Phys. Chem. 99 (1995) 8812-8816.

[58] M. Niwa, N. Katada, Chem. Rec. 13 (2013) 432-455.

[59] P. J. Becker, N. Serrand, B. Celse, D. Guillaume, H. Dulot, Comput. Chem. Eng. 98 (2017) 70-79.

[60] J.W. Thybaut, C. S. L. Narasimhan, J.F. Denayer, G.V. Baron, P.A. Jacobs, J.A. Martens, G.B. Marin, Ind. Eng. Chem. Res. 44 (2005) 5159-5169. 
Figures

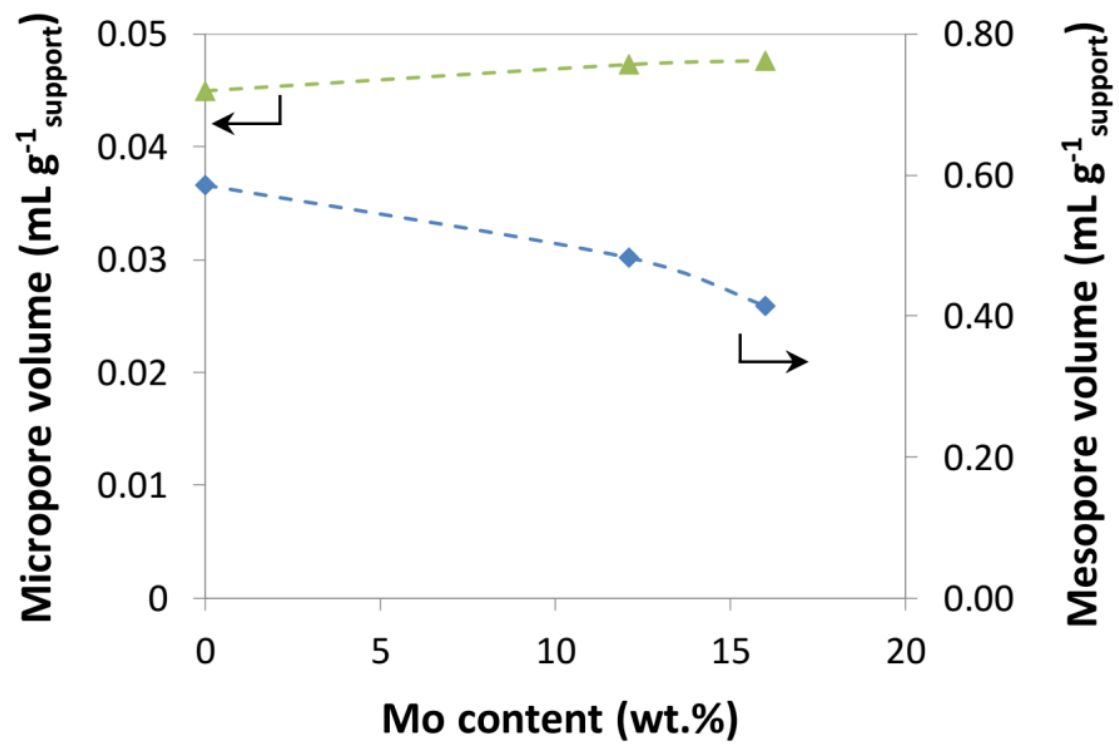

Figure 1: Volume of micropores and mesopores for shaped support [5] and corresponding NiMoP-impregnated samples determined by $\mathrm{N}_{2}$ adsorption-desorption. 

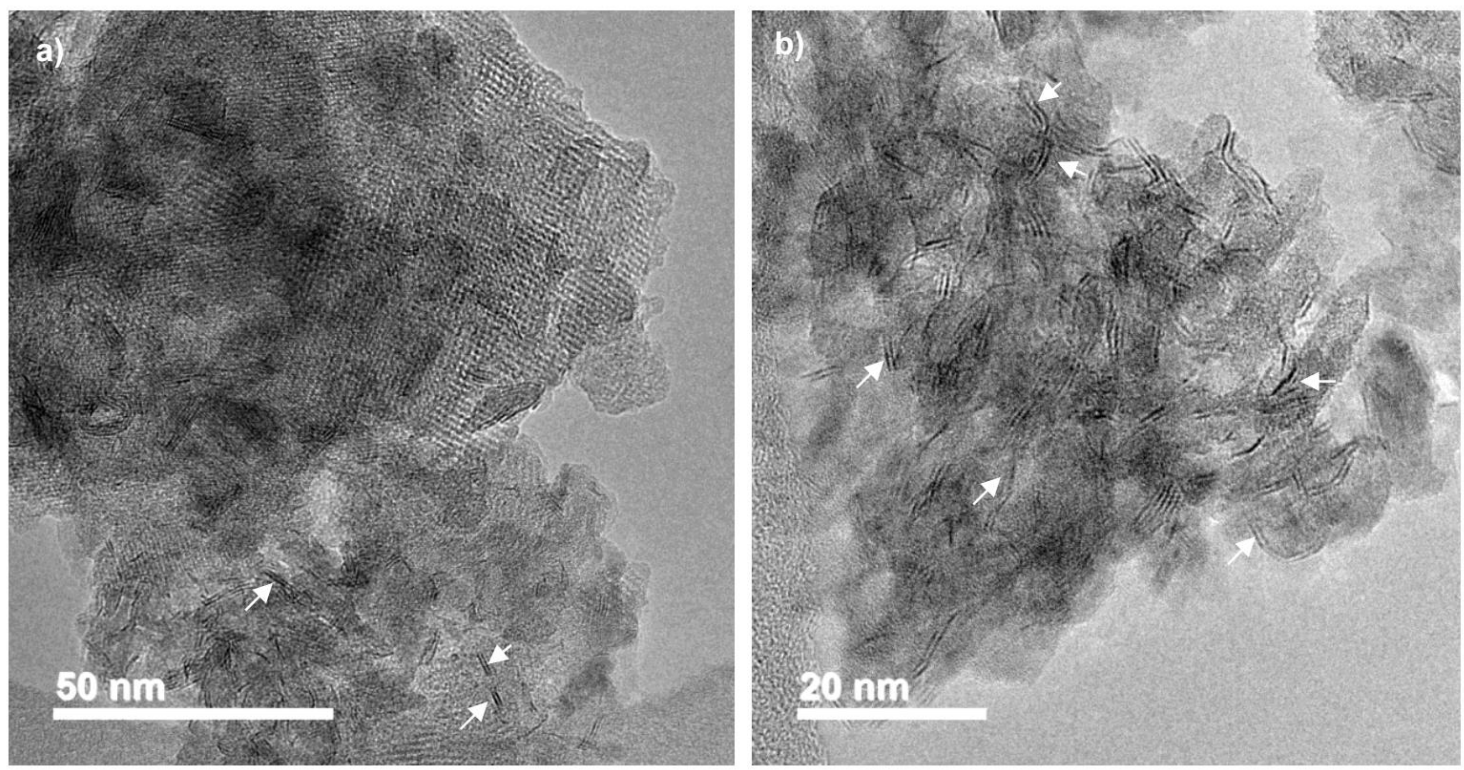

Figure 2: TEM micrographs of $12 \% \mathrm{NiMoS} /\left(\mathrm{HUSY}+\mathrm{Al}_{2} \mathrm{O}_{3}\right)$ sample in bright field mode. $\mathrm{MoS}_{2}$ nanocrystallites correspond to the agglomerates of alternate black and white fringes. Some $\mathrm{MoS}_{2}$ nanocrystallites are pointed out by arrows. 


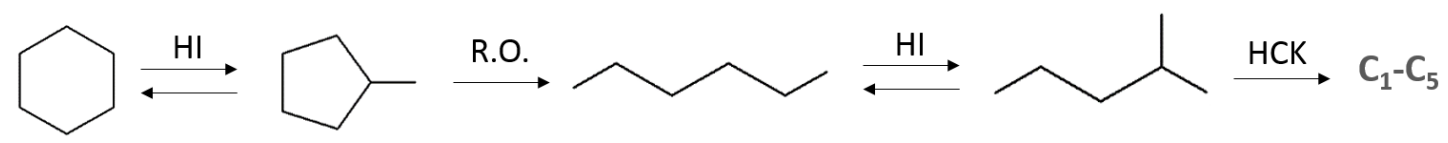

Figure 3: Simplified reaction scheme for cyclohexane hydroconversion. 

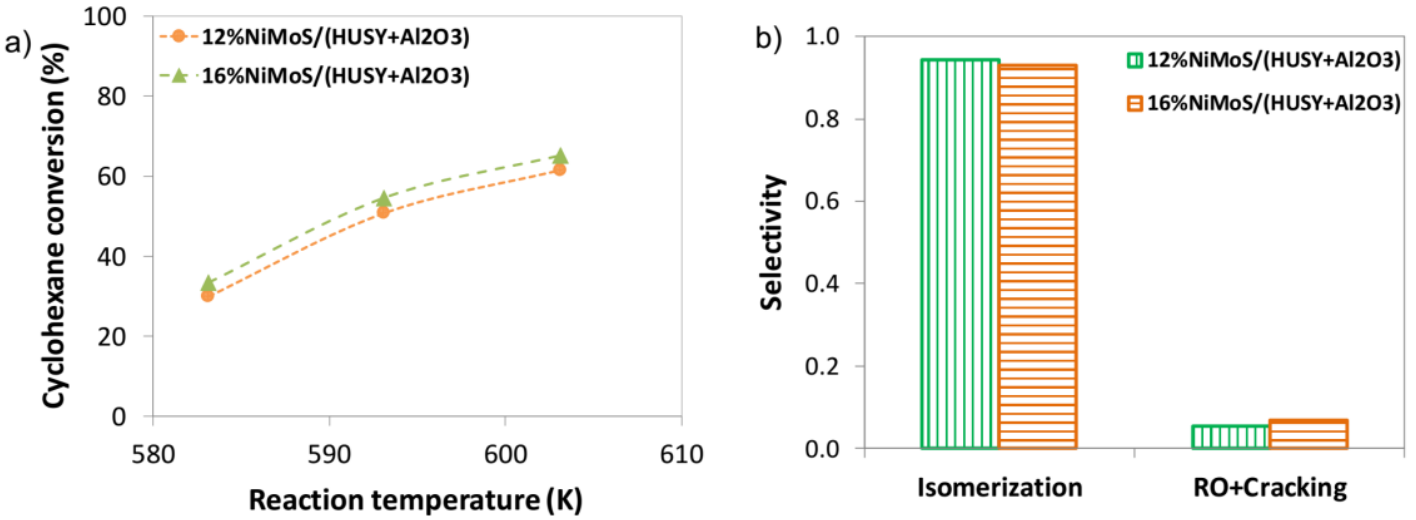

Figure 4: a) Cyclohexane hydroconversion as function of reaction temperature. b) Selectivity in lumped products at $593 \mathrm{~K}$ (cyclohexane conversion of $52 \%$ ). Reaction in absence of $\mathrm{NH}_{3}$ $\left(\mathrm{WHSV}=37 \mathrm{gcc}_{\mathrm{c} 6} \mathrm{~g}_{\text {zeolite }} \mathrm{h}^{-1} \mathrm{~h}^{-1}\right.$. 

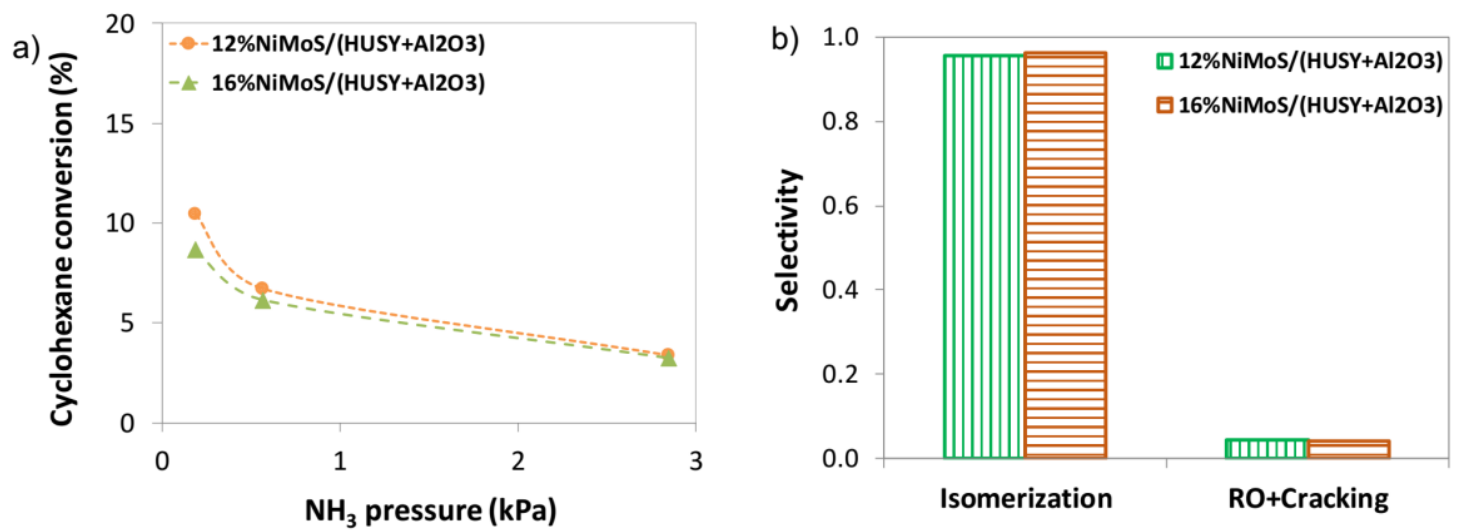

Figure 5: a) Cyclohexane conversion as function of $\mathrm{NH}_{3}$ partial pressure at $623 \mathrm{~K}$. b) Selectivity in lumped products at $623 \mathrm{~K}$ and $\mathrm{P}_{\mathrm{NH} 3}=2.8 \mathrm{kPa}$ (cyclohexane conversion of $3.2 \%$ ). (WHSV $=9.2$ gcc6 $\left.g_{\text {zeolite }}{ }^{-1} h^{-1}\right)$. 


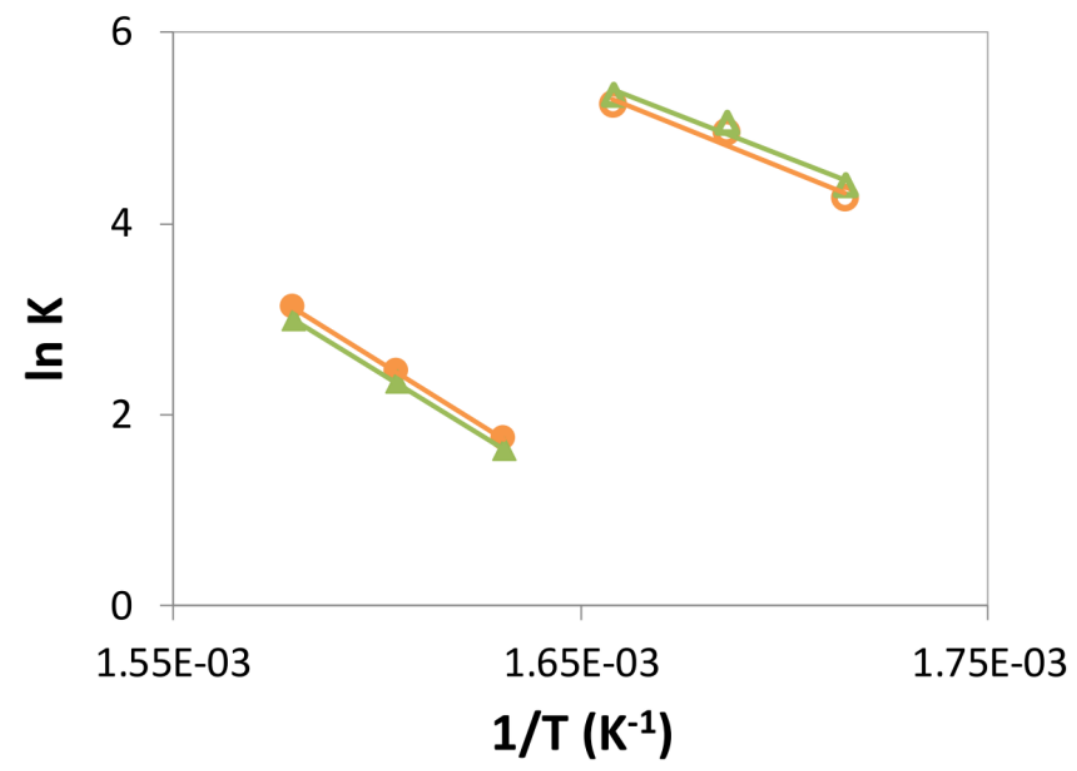

Figure 6: Arrhenius' plot of the apparent first-order kinetic constant for cyclohexane hydroconversion. Results over $\mathrm{NiMoS} /\left(\mathrm{HUSY}+\mathrm{Al}_{2} \mathrm{O}_{3}\right)$ catalysts with $12 \%$ (circles) and $16 \%$ (triangles) Mo contents either in presence of $2.8 \mathrm{kPa}$ of $\mathrm{NH}_{3}$ (closed symbols) or in absence of $\mathrm{NH}_{3}$ (open symbols). 


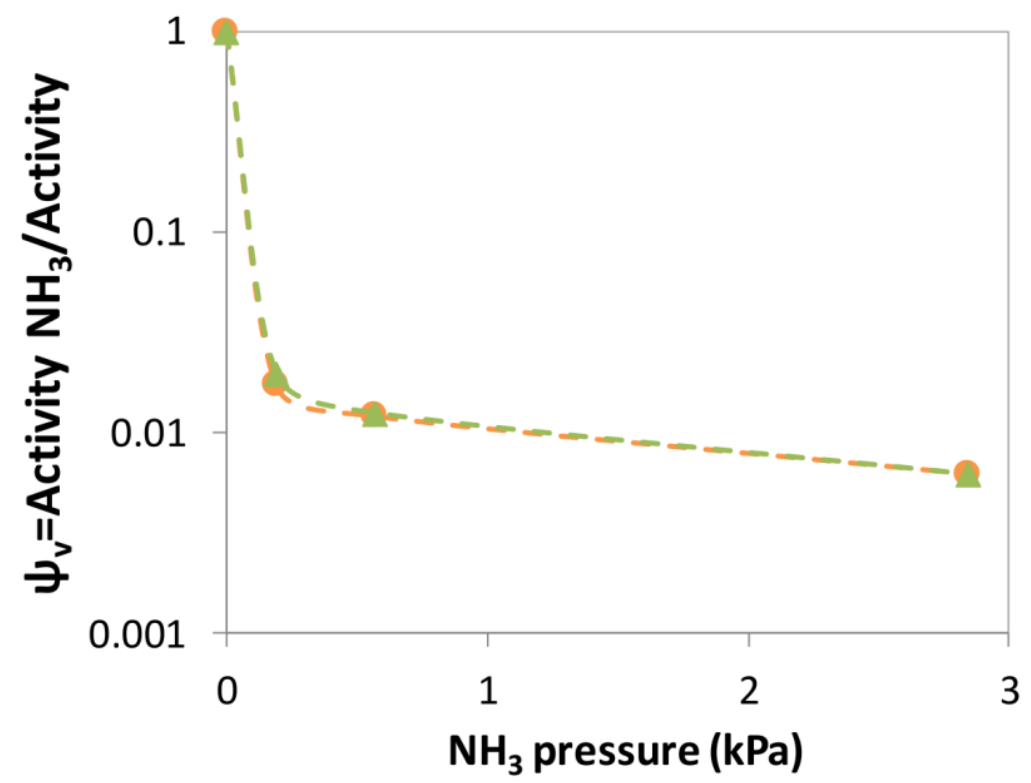

Figure 7: Fraction of vacant Brønsted acid sites in presence (Eq. 3) and in absence of $\mathrm{NH}_{3}$ in cyclohexane hydroconversion, for $12 \% \mathrm{NiMoS} /\left(\mathrm{HUSY}+\mathrm{Al}_{2} \mathrm{O}_{3}\right)$ (0) and $16 \% \mathrm{NiMoS} /\left(\mathrm{HUSY}+\mathrm{Al}_{2} \mathrm{O}_{3}\right)(\triangle)$ at $623 \mathrm{~K}$. 


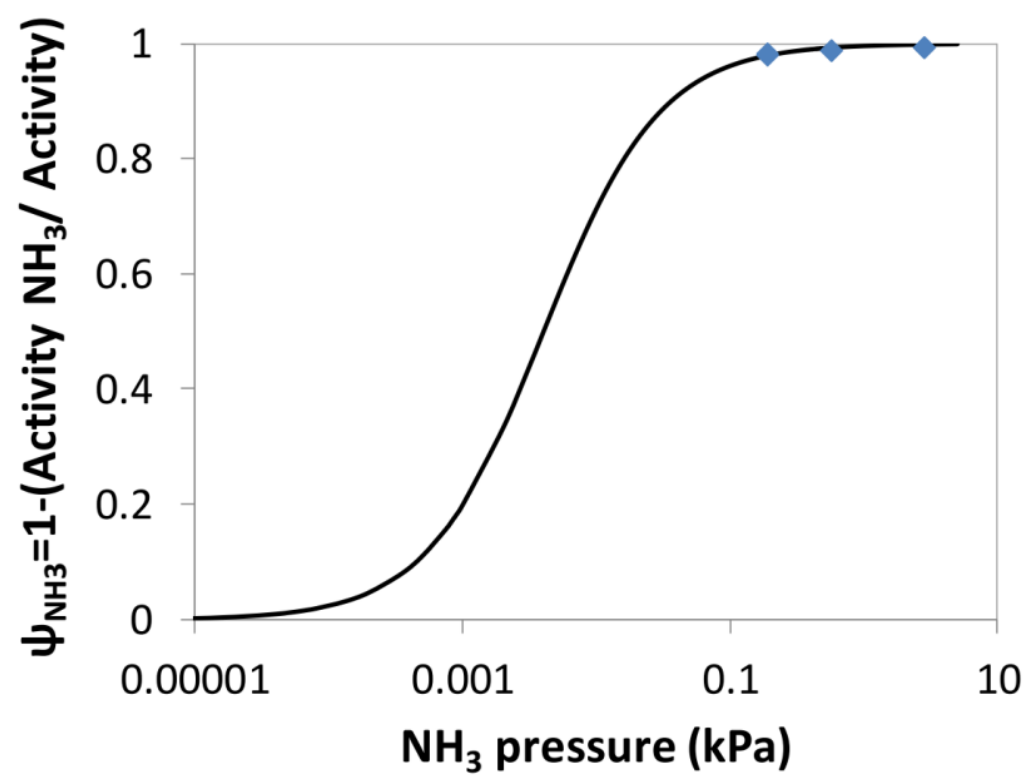

Figure 8: Fraction of Brønsted acid sites in HUSY zeolite inhibited by $\mathrm{NH}_{3}$ at $623 \mathrm{~K}$ (Eq. 4). As regressed via cyclohexane hydroconversion over $\mathrm{NiMoS} /\left(\mathrm{HUSY}+\mathrm{Al}_{2} \mathrm{O}_{3}\right)$ data: Langmuir isotherm (line) fitted to the experimental data (points). 

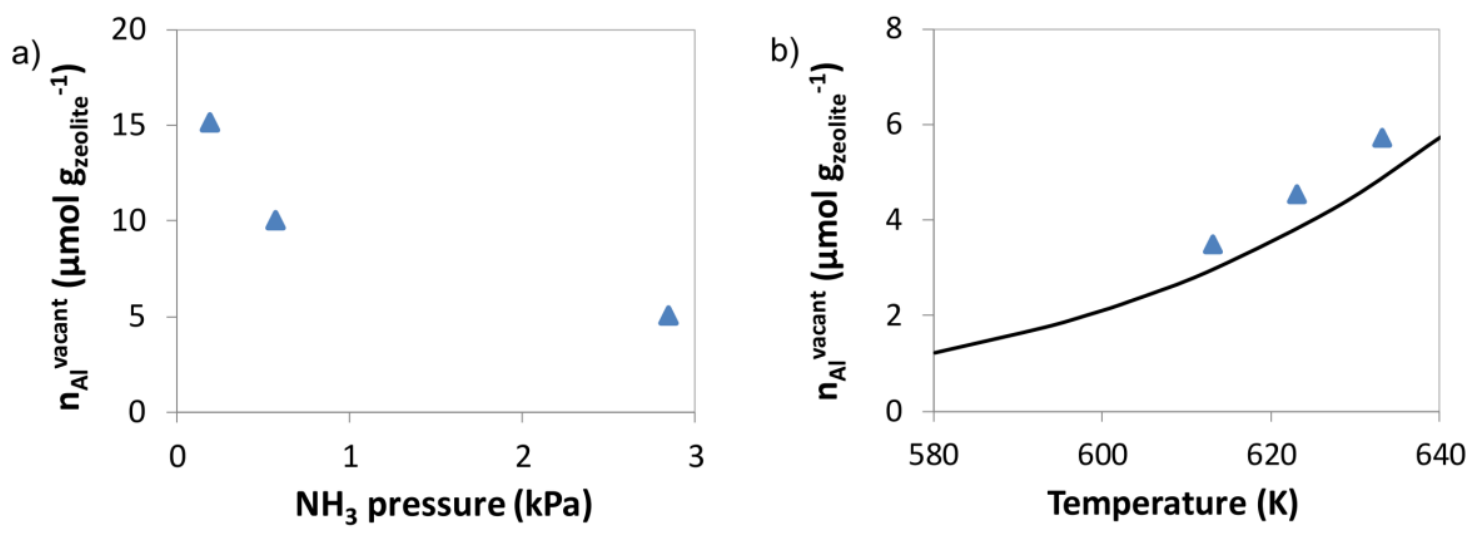

Figure 9: Concentration of vacant acid sites in HUSY zeolite a) inhibited by $\mathrm{NH}_{3}$ at $623 \mathrm{~K}$, and b) inhibited by $2.8 \mathrm{kPa}$ of $\mathrm{NH}_{3}$ at various temperature for cyclohexane hydroconversion over $\mathrm{NiMoS} /\left(\mathrm{HUSY}+\mathrm{Al}_{2} \mathrm{O}_{3}\right)$ catalysts (Eq. 3). Experimental data (points) and calculated values (line) via Arrhenius equation (Fig. 6). 


\section{Tables}

Table 1: Operating conditions for cyclohexane hydroconversion.

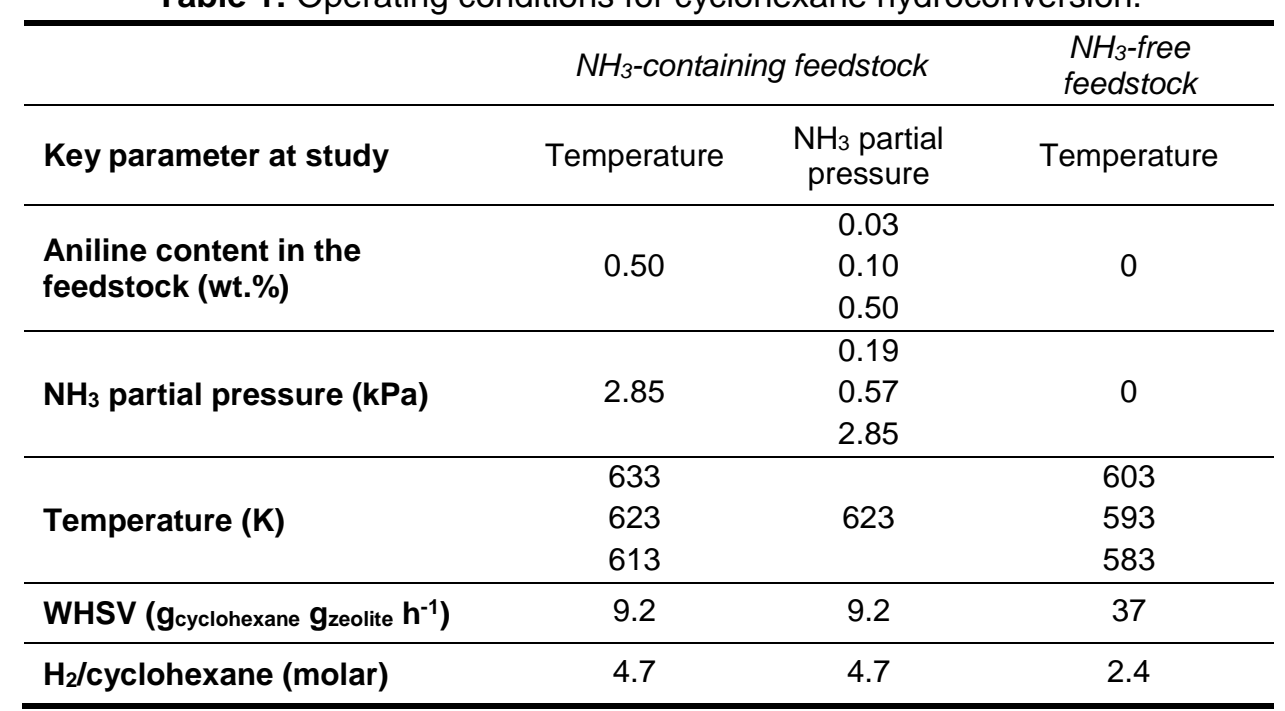


Table 2: Silicon, zeolite, and AlV concentration in shaped HUSY support.

\begin{tabular}{cccc}
\hline Formulation & $\begin{array}{c}\mathrm{Si} \\
(\mathrm{wt} . \%)\end{array}$ & $\begin{array}{c}\text { Zeolite }^{\mathrm{a}} \\
(\mathrm{wt} . \%)\end{array}$ & $\begin{array}{c}\mathrm{n}_{\mathrm{Al}}{ }^{\mathrm{b}} \\
\left(\mu \mathrm{mol} \text { support }^{-1}\right)\end{array}$ \\
\hline $\mathrm{Al}_{2} \mathrm{O}_{3}+\mathrm{HUSY}$ & 7.3 & 16.5 & 135 \\
\hline
\end{tabular}

a Using the amount of Si measured by $x$-ray fluorescence in parent zeolites.

${ }^{\mathrm{b}}$ Using $\left[\mathrm{Al}{ }^{\mathrm{IV}}\right]$ determined for parent zeolite [41]. 
Table 3: Composition of $\mathrm{NiMo} /\left(\mathrm{HUSY}+\mathrm{Al}_{2} \mathrm{O}_{3}\right)$ samples as measured by XRF, and metal distribution by EPMA.

\begin{tabular}{cccccc}
\hline $\begin{array}{c}\text { Mo } \\
\text { content } \\
\text { (wt.\%) }\end{array}$ & $\begin{array}{c}\text { Zeolite } \\
\text { (wt.\%) }\end{array}$ & $\begin{array}{c}\text { Ni/Mo } \\
\text { (atomic) }\end{array}$ & $\begin{array}{c}\text { P/Mo } \\
\text { (atomic) }\end{array}$ & $\begin{array}{c}\text { Distribution } \\
\text { coefficient } \\
\text { (Mo) }\end{array}$ & $\begin{array}{c}\text { Distribution } \\
\text { coefficient } \\
\text { (Ni) }\end{array}$ \\
\hline 12.0 & 11.9 & 0.40 & 0.49 & 0.98 & 0.98 \\
16.1 & 10.4 & 0.40 & 0.47 & 0.96 & 0.96 \\
\hline
\end{tabular}


Table 4: Composition of $\mathrm{NiMoS} /\left(\mathrm{HUSY}_{+} \mathrm{Al}_{2} \mathrm{O}_{3}\right)$ samples as measured by XPS, slab length by TEM, concentration of NiMoS sites, and metal to acid sites ratio.

\begin{tabular}{|c|c|c|c|c|c|c|}
\hline $\begin{array}{c}\text { Mo } \\
\text { content } \\
\text { (wt.\%) }\end{array}$ & $\begin{array}{c}\text { MoS }_{2} / \\
\text { Mooverall } \\
\text { (mol\%) } \\
\end{array}$ & $\begin{array}{l}\text { NiMoS/ } \\
\text { Niloverall } \\
\text { (mol\%) }\end{array}$ & $\begin{array}{l}\text { (Ni/Mo)slabs } \\
\text { (atomic) }\end{array}$ & $\begin{array}{c}\text { (Ni)MoS } 2 \\
\text { slab length } \\
(n m)\end{array}$ & $\begin{array}{l}\mathrm{n}_{\text {NiMos sites }} \\
\left(\mathrm{mmol} \mathrm{g}_{\mathrm{cat}}{ }^{-1}\right)\end{array}$ & $\begin{array}{l}\mathrm{n}_{\text {NiMos }} / \mathrm{n}_{\text {Al }} \\
(\mathrm{mol} / \mathrm{mol})\end{array}$ \\
\hline 12.0 & 69 & 55 & 0.30 & 3.2 & 0.28 & 2.9 \\
\hline 16.1 & 73 & 51 & 0.28 & 3.5 & 0.34 & 4.0 \\
\hline
\end{tabular}


Table 5: Metal to acid sites molar ratio ( $\left.\mathrm{n}_{\mathrm{Nimos}} / \mathrm{n}_{\mathrm{Al}}\right)$ for $12 \% \mathrm{NiMoS} /\left(\mathrm{HUSY}+\mathrm{Al}_{2} \mathrm{O}_{3}\right)$ catalyst under reaction conditions.

\begin{tabular}{|r|c|c|}
\hline $\begin{array}{r}\mathbf{N H}_{3} \text { partial } \\
\text { pressure } \\
\mathbf{( k P a )}\end{array}$ & $\mathbf{0}$ & $\mathbf{2 . 8}$ \\
\hline Temperature (K) & & \\
\hline $\mathbf{5 9 3}$ & 2.9 & 2620 \\
\hline $\mathbf{6 0 8}$ & 2.9 & 1760 \\
\hline $\mathbf{6 2 3}$ & 2.9 & 902 \\
\hline
\end{tabular}

